\title{
STRUKTUR, FUNGSI, DAN MAKNA MANTRA PENGASIH DIRI DI DESA SUNGAI NYIRIH, KECAMATAN SELAKAU SERTA IMPLEMENTASINYA DI SEKOLAH
}

\author{
Zulfahita \\ Program Studi Pendidikan Bahasa dan Sastra Indonesia, STKIP Singkawang \\ Corresponding Email: Zulfahita@yahoo.co.id
}

Received: 7th of August 2020, Accepted: $1^{\text {st }}$ of December 2020, Published: 11th of December 2020

\begin{abstract}
Abstrak
Penelitian ini bertujuan untuk mendeskripsikan struktur, fungsi, dan makna mantra pengasih diri di Desa Sungai Nyirih, Kecamatan Selakau. Metode penelitian menggunakan metode deskriptif dengan bentuk kualitatif, menggunakan pendekatan struktural. Alat pengumpulan data menggunakan lembar observasi, wawancara. Teknik menganalisis data dalam penelitian ini pentranskripsian, pengklasifikasian data, penganalisisan, penyimpulan. Berdasarkan hasil analisis data dilakukan pada 15 mantra pengasih diri diperoleh hasil sebagai berikut. Pada 15 mantra yang diteliti terdapat struktur mantra yaitu unsur judul, pembuka, niat, sugesti, tujuan, dan penutup, dengan fungsi pada mantra terdapat 1 kutipan berfungsi sebagai penakluk kejahatan, 13 kutipan berfungsi sebagai pengisi kekuatan supranatural, 15 kutipan berfungsi sebagai media komunikasi dengan tuhan, 7 kutipan berfungsi sebagai pemikat asmara, dan 2 kutipan berfungsi sebagai pembelenggu roh manusia dan jin. Sedangkan makna mantra yang terdapat pada 15 mantra tersebut bermakna konotatif. Penelitian ini diimplementasikan pada SMP kelas VII semester ganjil, dengan KD 3.14 dan 4.14 materi puisi rakyat.
\end{abstract}

Kata Kunci: Struktur, fungsi, makna mantra pengasih diri

\begin{abstract}
This study aims to describe the structure, function, and meaning of self-compassion mantra in Nyirih river Village, Selakau District. The research method used a descriptive method with a qualitative form, using a structural approach. Data collection tools using observation sheets, interviews. The technique of analyzing data in this research is transcription, data classification, analysis, and inference. Based on the results of data analysis carried out on 15 self-compassion mantras, the following results were obtained. In the 15 spells studied, there are spell structures, namely the elements of title, opening, intention, suggestion, purpose, and closing, with the function of the mantra, 1 quote serves as a conqueror of evil, 13 quotes serve as filler of supernatural powers, 15 quotes serve as a medium of communication with God, 7 quotes serve as a charm for romance, and 2 quotes serve as shackles for the human spirit and the jinn. While the meaning of the mantra contained in the 15 mantras has a connotative meaning. This research was implemented in the seventh grade junior high school odd semester, with KD 3.14 and 4.14 material of folk poetry.
\end{abstract}

Keywords: structure, function, and the meaning of the mantra of self-compassion

Copyright $\odot 2020$ Zulfahita, Galih Novianti 


\section{PENDAHULUAN}

Karya sastra merupakan hasil imajinasi seseorang dalam bentuk lisan ataupun tulisan. Karya sastra menurut Wicaksono (dalam Novita dkk, 2019:40) merupakan potret kehidupan masyarakat dapat dinikmati, dipahami, dan dapat dimanfaatkan oleh masyarakat. Sebuah karya satra dapat tercipta karena adanya pengalaman batin pengarang berupa peristiwa atau problem yang menarik sehingga muncul gagasan dan imajinasi yang dituangkan dalam bentuk tulisannya termasuk karya sastra berupa fiksi. Karya sastra sudah hadir sejak ribuan tahun yang lalu yang dinilai sebagai satu di antara cabang kesenian yang beragam, hingga sampai saat ini sastra tidak hanya dinilai sebagai sebuah karya seni yang biasa, tapi telah dianggap suatu karya kreatif yang dimanfaatkan sebagai konsumsi intelektual disamping konsumsi emosi. Karya sastra sudah dikatakan populer sebagai satu di antara bentuk karya seni yang diangkat melalui sebuah kreativitas seorang pengarang. Hasil imajinasi pengarang tersebut diungkapkan ke dalam karya untuk dihidangkan kepada masyarakat pembaca agar bisa dinikmati, dipahami, dan dimanfaatkan. Sastra terbagi menjadi dua yaitu sastra lisan dan sastra tulis, sastra lisan adalah kesusastraan yang mencakup ekspresi kesusastraan warga suatu kebudayaan yang disebarkan dan diturun-temurunkan dari mulut ke mulut.

Sastra lisan adalah karya yang penyebarannya disampaikan dari mulut ke mulut, sastra lisan biasanya lahir dari masyarakat yang masih bersifat tradisional, kental akan budaya dan lebih menekankan sifat khayalan yang magis. Sastra lisan merupakan suatu teks yang berbentuk estetik dan disampaikan secara turun temurun. Sastra lisan dibawakan atau ditampilkan oleh seniman sastra lisan, hal itu senada dengan pendapatnya Taum (dalam Sulistyorini dan Eggy, 2017: 12), sastra lisan adalah teks yang disebarkan dan diturun-temurunkan secara lisan yang mengandung sarana-sarana kesusastraan dan memiliki efek estetik dalam kaitannya dengan konteks moral maupun kultural dari sekelompok masyarakat tertentu.

Mantra menurut Amir (dalam Hafid dkk, 2019:130) adalah sastra yang eksklusif, pembacaan dan teksnya bersifat khusus dan terikat, lafalnya tidak jelas, memiliki kekuatan magis, dan ada akibat nyata atas pelaksanaanya. Mantra merupakan satu di antara sastra lisan, yang mana penyampaiannya ini melalui lisan atau disampaikan secara lisan. Mantra ini bisa berupa suatu pujian-pujian yang cara penyampaiannya adalah dengan menggunakan kalimat halus. Sejalan dengan pendapat Zaidan dkk (dalam Hamidin, 2016:7) mengemukakan bahwa mantra adalah puisi melayu yang dianggap mengandung kekuatan gaib, yang biasanya diucapkan oleh pawang atau dukun untuk mempengaruhi kekuatan alam semesta dan binatang. Mantra biasanya digunakan atau diucapkan pada waktu dan tempat tertentu yang memiliki tujuan untuk menimbulkann suatu kemampuan tertentu bagi orang yang menggunakan atau mengucapkan mantra tersebut. 
Sebuah karya sastra memiliki susunan unsur-unsur dan struktur sendiri, yang antara unsurunsurnya terjadi hubungan yang timbal balik, saling menentukan. Menurut Siswantoro (2011: 13) struktur adalah bentuk keseluruhan yang kompleks". Struktur dalam mantra merupakan unsurunsur pembangun mantra secara garis besar struktur mantra menurut Anggoro (2011: 24) terdiri dari enam bagian meliputi unsur judul, unsur pembuka, unsur niat, unsur sugesti, unsur tujuan dan unsur penutup. Setiap kalimat dalam mantra memiliki fungsi masing-masing yang berbeda-beda. Makna menurut Keraf (dalam Sulistyorini dan Eggy, 2017: 46) pengertian yang tersirat dalam sebuah kata mengandung makna bahwa setiap kata mengungkapkan sebuah gagasan atau sebuah ide. Dengan kata lain, kata-kata adalah alat penyaluran gagasan yang akan disampaikan kepada orang lain. Mantra yang akan dikaji oleh penulis adalah mantra pengasih. Mantra pengasih merupakan mantra yang bertujuan untuk membuat orang menjadi tunduk atau patuh terhadap seseorang sesuai dengan keinginannya. Adapun mantra pengasih sebagai objek kajian dalam penelitian ini adalah pertama, mantra pengasih yang ada dimasyarakat desa sungai Nyirih masih dipercaya memiliki kekuatan gaib bagi penggunanya. Kedua, penelitian mantra jarang diteliti, sehingga harus diletarikan agar generasi muda yang akan datang tahu akan perkembangan mantra. Ketiga, penulis ingin menggali lebih dalam mengenai mantra pengasih dan ingin mengembangkan budaya yang ada di Desa Sungai Nyirih Kecamatan selakau Kabupaten Sambas. Dengan adanya penelitian ini diharapkan dapat dijadikan motivasi bagi penulis untuk semakin aktif untuk meyumbangkan hasil karya ilmiah yang berkenaan dengan kesastraan, dapat dijadikan bahan bacaan untuk memperluas pengetahuan pembaca mengenai persepsi masyarakat terhadap mantra yang ada di Desa Sungai Nyirih Kecamatan Selakau Kabupaten Sambas.

\section{METODE}

Metode penelitian yang digunakan pada penelitian ini adalah metode deskriptif yang digunakan untuk mendeskripsikan atau menggambarkan secara rinci dan mendalam mengenai data yang dikumpulkan berupa rangkaian kata atau kalimat dan bukan urutan angka. Menurut Moleong (2012:11) yang menyatakan metode deskriptif adalah data yang dikumpulkan adalah berupa katakata, gambar, dan bukan angka-angka. Hal itu disebabkan oleh adanya penerapan metode kualitatif. Selain itu, semua yang dikumpulkan berkemungkinan menjadi kunci terhadap apa yang sudah diteliti. Moleong (2012:6) menyatakan bahwa "Penelitian Kualitatif merupakan penelitian yang bermaksud untuk memahami fenomena tentang apa yang dialami oleh objek penelitian misalnya perilaku, persepsi, motivasi, tindakan secara holistik dan dengan cara deskripsi dalam 
bentuk kata-kata dan bahasa. Bentuk penelitian kualitatif dalam penelitian ini yang menjelaskan fenomena dari rangkaian kata-kata berupa informasi yang didapat dari tuturan informan.

Pendekatan yang digunakan adalah pendekatan struktural, dengan sumber data dua informan yang berasal dari Desa Sungai Nyirih. Pada penelitian ini peneliti mengambil dua informan dengan latar belakang informan pertama yaitu dua orang laki-laki yang berprofesi sebagai pemuka adat dan dukun di daerah setempat. Kedua informan tersebut menjadi sumber data dalam penulisan ini yang penulis pilih untuk menuturkan mantra. Teknik pengumpulan data dilakukan dengan teknik observasi langsung, teknik perekaman, dan teknik studi dokumentasi. Alat pengumpulan data dalam penelitian ini menggunakan lembar observasi, pedoman wawancara, dan dokumentasi. Analisis data dilakukan dengan empat langkah sebagai berikut.

1. Pentranskripsian

2. Pengklasifikasian data

3. Penganalisisan

4. Pengumpulan

Pengecekan keabsahan data dalam penelitian ini adalah: tringulasi sumber data yaitu dengan melakukan wawancara lebih mendalam kepada pemuka adat dan dukun, kecukupan referensi, serta diskusi teman sejawat.

\section{HASIL DAN PEMBAHASAN}

Adapun hasil penelitian tentang struktur mantra Pengasih diri desa Sungai Nyirih Kecamatan Selakau kabupaten Sambas, terdapat 15 mantra pengasih diri yang ada di desa Sungai Nyirih yaitu:
a. Mandi Ular Cintamani,
b. Mandi Syahadat Siti Fatimah,
c. Mandi Suci Fatimah,
d. Mandi Penahan Badan,
e. Penahan badan,
f. Minum Bukuk Kunyit,
g. Mandi Saidina Ali,
h. Mandi Seh embun,
i. Ilmu Pengasih Seorang,
j. terkaseh sekampong,
k. Ilmu Penunduk,
1. Buluh Perindu,
m. Pantan,
n. Ilmu Penyatuan Cerai, dan
o. Peninding Badan.

Ke-15 mantra tersebut dianalisis untuk mengetahui struktur, fungsi dan makna mantranya, dimana 15 mantra tersebut masing-masing memiliki 6 struktur yaitu unsur judul, unsur pembuka, 
unsur niat, unsur sugesti, unsur tujuan, dan unsur penutup, terdapat 6 fungsi mantra dari 12 fungsi mantra yang ada, yaitu: 1 kutipan mantra berfungsi sebagai penakluk kejahatan, 13 kutipan mantra berfungsi sebagai pengisi kekuatan supranatural, 15 kutipan mantra berfungsi sebagai media komunikasi dengan tuhan, 7 kutipan mantra berfungsi sebagai pemikat asmara, dan 2 kutipan mantra berfungsi sebagai pembelenggu roh manusia dan jin. Sedangkan makna mantra yang terdapat pada 15 mantra tersebut bermakna konotatif. Penelitian ini diimplementasikan pada SMP kelas VII semester ganjil, dengan KD 3.14 dan 4.14 materi puisi rakyat.

Berdasarkan hasil penelitian tentang struktur, fungsi, dan makna mantra pengasih diri di Desa Sungai Nyirih Kecamatan Selakau terdapat 15 mantra pengasih diri. Penulis menganalisis 6 struktur pembangun menurut Anggoro (2011:24) terdiri dari enam yaitu unsur judul, unsur pembuka, unsur niat, unsur sugesti, unsur tujuan, dan unsur penutup. Serta fungsi menururt sukatman (2009:62) terdapat 12 fungsi yaitu, sebagai penakluk kejahatan, penjaga wibawa, pengisi kekuatan supranatural, penolak balak, pemikat asmara, penghubung dalam sesaji, penghantar roh manusia ke dalam arwah, pembawa kutukan, pembelenggu roh manusia dan jin, media komunikasi dengan Tuhan, penawar racun, dan penakluk binatang galak. Serta makna menurut Keraf (dalam Sulistyorini dan Eggy, 2017: 46) pengertian yang tersirat dalam sebuah kata mengandung makna bahwa setiap kata mengungkapkan sebuah gagasan atau ide, penulis disini menggunakan makna denotatif (makna sebenarnya) dan makna konotatif (bukan makna sebenarnya). Berikut pembahasan mengenai satu di antara 15 mantra pengasih diri yang sudah dianalisis.

\section{Struktur Pembangun Mantra Pengasih Diri di Desa Sungai Nyirih Kecamatan Selakau}

Struktur pembangun mantra terdiri dari enam unsur meliputi: Unsur judul, unsur pembuka, unsur niat, unsur sugesti, unsur tujuan, dan unsur penutup (Anggoro, 2011: 24). Penelitian tentang struktur mantra juga pernah diteliti oleh Triani, dkk., (2020) yang meneliti struktur dalam mantra Dayak Salako di Desa Bagak Sahwa Kecamatan Singkawang Timur. Adapun hasil penelitian dalam mantra pengasih diri sebagai berikut.

\section{Mantra Mandi Ular Cintamani}

\section{Bissmillahirrahmanirrahim}

Air Segodak Godam

Air Mandi Saya Mandikan

Mandi Air Setana Rupa

Hujan Panas Hujan Tarekat

Hujan Menikam Ke Batu

Aku Makai Cahaye Mak Ripat

Tiada Lepas Burung Pingai Yang Ramai Memandang Aku

Sidi Guru, Sidi Aku, Sidi Mani Pelajar 


\section{Guru $\mathrm{Ku}$}

Licin Linyau Sring

Kuning Tubuh Badanku

Seperti Tubuh Ular Cintamani

Kurrsss Semangat Makhluk Mahlike

Yang Ramai Lalai Like Memandang Aku

Kunaikkan Cahaye Bidadari

Kemukaku Sri Melimpah Ke Tubuhku

Sri Allah Sri Muhammad Sri Baginda Rasulullah

Berkat Aku Memakai Doa Lailahaillallah Muhammadarrasulullah

\section{Terjemahan:}

Dengan menyebut nama Allah yang Maha pengasih dan Penyayang

Air seember besar

Air mandi untuk dimandikan

Mandi semuka

Hujan panas hujan terikat

Hujan menghantam batu

Aku menggunakan cahaya mak Ripat

Tidak lepas burung pingai yang ramai memandang aku

Satu guru, satu aku, satu mani pelajar

Guru ku

Licin bersih mengkilat

Kuning tubuh badanku

Seperti tubuh Ular Cintamani

Kurss semangat makhluk ciptaan Allah

Yang ramai lewat memandang aku

Kunaikkah cahaya bidadari

Kemukaku Sri melimpah ke tubuhku

Sri Allah Sri Muhammad Sri Baginda Rasulullah

Berkat aku menggunakan Doa Lailahaillallah Muhammadarrasulullah

1) Unsur judul

"Mandi Ular Cintamani” mantra yang berjudul mandi ular cintamani memiliki arti yaitu mantra yang mempercantik untuk seluruh makhluk. Jadi mantra ini bisa membuat seluruh makhluk mengasihi menyukai dan menyayangi kita.

2) Unsur pembuka

“Bismillahirrahmanirrahim” (baris ke 1)

Kata bismillahirrahmanirrahim menjadi kata yang mengawali pembacaan mantra yang artinya dengan menyebut nama Allah yang maha pengasih dan penyayang. Kata pembuka tersebut diucapkan sebelum memasuki kalimat mantra yang bertujuan agar apapun yang dilaksanakan akan menghasilkan hal-hal baik dan segala sesuatunya yang kita inginkan harus meminta kepada yang Maha Kuasa.

3) Unsur niat 


\section{“tiada lepas burung pingai yang ramai memandang aku” (baris ke 8)}

Kalimat tersebut menjadi unsur niat pada mantra ini yang artinya tidak lepas burung pingai yang ramai memandang aku menandakan keinginanndari mantra ini adalah memiliki tubuh yang sangat cantik sehingga menjadi pusat perhatian orang lain.

4) Unsur sugesti

“aku mekai cahaye mak Ripat, kruss semangat makhluk mahlike kunaikkan cahaye bidadari” (baris ke 7)

Kalimat tersebut menjadi unsur sugesti yang dianggap memiliki kekuatan gaib bagi pengguna mantra, pada kalimat tersebut jelas memanggil makhluk lain selain manusia untuk memberikan kekuatan bagi penggunanya. arti dari kalimat tersebut adalah aku menggunakan cahaya dari mak Ripat (makhluk lain) kruss semangat seluruh makhluk kunaikkah cahaya bidadari.

5) Unsur tujuan

"kuning tubuh badanku seperti tubuh ular cintamani, kruss semangat makhluk mahlike yang ramai lalai like memandang aku” (baris ke 14)

Kalimat tersebut menjadi unsur tujuan pada mantra ini yang artinya kuning bersinar seluruh tubuhku seperti ular cintamani, kruss semangat seluruh makhluk yang ramai memandang aku. Tujuan dari pemantra adalah membuat dirinya menjadi pusat perhatian orang-orang yang berlalu lalang untuk selalu memandang tubuhnya yang terlihat bersinar dan cantik.

6) Unsur penutup

"sri Allah sri Muhammad sri Baginda Rasulullah, berkat aku memakai doa Laailahaillallah Muhammadarrasulullah” (baris ke 18)

Kalimat tersebut menjadi akhir dari pembacaan mantra yang artinya cahaya Allah cahaya Muhammad dan cahay Baginda Rasulullah berkat aku menggunakan doa tiada Tuhan selain Allah dan Nabi Muhammad utusan Allah. Kalimat ini menjadi penutup mantra kerena pemantra tak lain hanya meminta pertolongan dengan Allah atas apa yang diinginkannya.

\section{Fungsi Mantra Pengasih Diri di Desa Sungai Nyirih Kecamatan Selakau}

Mantra dalam eksistensinya dalam kehidupan manusia memiliki fungsi, baik bagi dukun maupun bagi masyarakat. Adapun untuk mengetahui fungsi mantra, menurut Sukatman (2009: 62) mengatakan fungsi mantra sebagai berikut. a) sebagai penakluk kejahatan, b) penjaga wibawa, c) pengisi kekuatan supranatural berupa "yoni” (tuah), d) penolak kutukan (balak), e) pemikat asmara, f) penghubung dalam sesaji, g) penghantar roh manusia ke dalam arwah, h) pembawa kutukan, i) pembelenggu roh manusia dan jin, j) media komunikasi dengan tuhan, k) penawar racun, 1) penakluk binatang galak. Penelitian tentang fungsi mantra juga 
pernah diteliti oleh Triani, dkk., (2020) yang meneliti fungsi dalam mantra Dayak Salako di Desa Bagak Sahwa Kecamatan Singkawang Timur. Adapun hasil penelitian dalam mantra pengasih diri sebagai berikut.

\section{Mantra Mandi Ular Cintamani}

a. Berfungsi sebagai Pemikat asmara

“aku menggunakan cahaya mak Ripat tidak lepas burung pingai yang ramai memandang $\boldsymbol{a k u}$ ” (baris ke 7)

Kutipan tersebut berfungsi untuk memikat lawan jenisnya, artinya jika mantra ini berhasil diamalkan maka bisa memikat asmara kepada laki-laki maupun perempuan.

b. Berfungsi sebagai Penakluk binatang galak

\section{“kuning tubuh badanku seperti tubuh ular cintamani” (baris ke 14)}

kutipan tersebut seusia dengan judulnya yaitu mantra yang memiliki arti untuk mempercantik serta membuat seluruh manusia bahkan hewan akan menyukai kita. Ketikan mantra ini diucapkan bisa berfungsi untuk menaklukkan binatang galak seperti ular yang akan menjadi jinak terhadap kita.

c. Berfungsi sebagai Media komunikasi dengan Tuhan

"sri Allah si Muhammad sri Baginda Rasulullah, berkat saya menggunakan doa laa ilaahailallah muhammadarrasulullah" (baris ke 19)

Kutipan tersebut berfungsi sebagai media komunikasi dengan Tuhan, lewat ini pemantra meminta izin kepada Allah untuk mengabulkan permintaanya. Karena segala sesuatunya yang dilakukan adalah atas kehendak dari Allah.

\section{Makna mantra pengasih diri di Desa Sungai Nyirih Kecamatan Selakau}

Menurut Keraf (dalam Sulistyorini dan Eggy, 2017: 46) pengertian yang tersirat dalam sebuah kata mengandung makna bahwa setiap kata mengungkapkan sebuah gagasan atau sebuah ide. Atau dengan kata lain, kata-kata adalah alat penyaluran gagasan yang akan disampaikan kepada orang lain. Makna merupakan maksud yang terkandung dalam teks. Makna mantra adalah apa maksud dan tujuan dari suatu mantra. Makna dalam ilmu linguistic dikenal dengan sebutan semantik. Keraf (2010:25) menyatakan bahwa makna adalah segi yang menimbulkan reaksi dalam pikiran pendengar atau pembaca karena rangsangan bentuk aspek. Untuk menganalisis mantra Pengasih Diri Desa Sungai Nyirih Kecamatan Selakau Kabupaten Sambas, peneliti menggunakan jenis makna yang dilihat berdasarkan ada atau tidaknya nilai rasa dalam sebuah kata. Adapun hasil analisis makna pada mantra pengasih diri sebagai berikut. 


\section{Mantra Mandi Ular Cintamani}

Mantra ini memiliki makna yang disampaikan secara langsung yaitu membuat semua orang menjadi menyukai dan menyayangi diri kita bahkan seluruh manusia hingga hewan akan memiliki perasaan suka dan menyayangi kita, namun pada mantra ini hanya terdapat makna makna konotatif (bukan makna sebenarnya) karena setiap baris mantra memiliki kekuatan magis, bahasa yang digunakan menggunakan bahasa kias.

\section{Implementasi Hasil Penelitian pada Rencana Pelaksanaan Pembelajaran Bahasa Indonesia di Sekolah}

Penelitian ini dapat diimplementasikan pada pembelajaran berdasarkan kurikulum 2013 dengan Kompetensi Dasar 3.14 Menelaah Struktur dan Kebahasaan puisi rakyat (pantun, syair, dan puisi rakyat setempat) yang di baca dan di dengar. 4.14 Mengungkapkan gagasan, perasaan, pesan dalam bentuk puisi rakyat secara lisan dan tulis dengan memperhatikan struktur, rima, dan penggunaan bahasa dengan aspek tujuan pembelajaran sastra yaitu setelah melakukan proses pembelajaran siswa diharapkan mampu 1) menentukan bagian-bagian struktur teks puisi rakyat yang disajikan secara tepat, 2) menentukan susunan teks puisi rakyat secara tepat, 3) menentukan unsur kebahasaan dalam puisi rakyat, 4) menulis teks puisi rakyat dengan memperhatikan pilihan kata, kelengkapan struktur dan kaidah penggunaan kalimat atau tanda baca atau ejaan dengan tepat, 5) menyajikan secara lisan teks puisi rakyat dalam konteks bercerita dengan benar.

Serta aspek keterbacaan teks dapat dilihat dari penggunaan bahan ajar disesuaikan dengan jenjang pendidikan yang ditempuh oleh siswa pada aspek ini peneliti menjelaskan mengenai jenis-jensi puisi lama satu di anatarnya mantra, lalu memberikan contoh teks mantra dan menentukan unsur pembangun serta makna yang terkandung dalam teks mantra tersebut.

\section{SIMPULAN}

Berdasarkan analisis data dan hasil yang dilakukan dapat disimpulkan bahwa struktur pembangun dalam mantra pengasih diri di Desa Sungai Nyirih Kecamatan Selakau yaitu: a. unsur judul, b. unsur pembuka, c. unsur niat, d. unsur sugesti, e. unsur tujuan, dan f. unsur penutup. Setelah menganalisis lima belas mantra pengasih diri desa Sungai Nyirih Kecamatan Selakau dapat disimpulkan bahwa ke 15 mantra yang ada di Desa Sungai Nyirih Kecamatan Selakau ini masingmasing memiliki semua unsur pembangun struktur mantra.

Setelah menganalisis lima belas mantra pengasih diri yang ada di Desa Sungai Nyirih Kecamatan Selakau terdapat 6 fungsi mantra dari 12 fungsi mantra yang ada, yaitu: 1 kutipan 
mantra berfungsi sebagai penakluk kejahatan, 13 kutipan mantra berfungsi sebagai pengisi kekuatan supranatural, 15 kutipan mantra berfungsi sebagai media komunikasi dengan tuhan, 7 kutipan mantra berfungsi sebagai pemikat asmara, dan 2 kutipan mantra berfungsi sebagai pembelenggu roh manusia dan jin.

Makna dalam mantra pengasih diri desa Sungai Nyirih Kecamatan Selakau dianalisis berdasarkan jenis makna yang dilihat berdasarkan ada atau tidaknya "nilai rasa" dalam sebuah kata maupun kalimat. Makna tersebut ialah, makna denotatif (makna sebenarnya) dan makna konotatif (bukan makna sebenarnya). Setelah melakukan penganalisisan pada 15 mantra pengasih diri dapat ditarik kesimpulan bahwa semua mantra pengasih diri mengandung kata yang belum diketahui makna sebenarnya atau yang biasa disebut dengan makna konotatif. Penelitian ini dapat diimplementasikan pada pembelajaran, pertama dapat ditinjau dari aspek pembelajaran sastra berdasarkan kurikulum(K13) dengan Kompetensi Dasar 3.14 Menelaah Struktur dan Kebahasaan puisi rakyat (pantun, syair, dan puisi rakyat setempat) yang di baca dan di dengar. 4.14 Mengungkapkan gagasan, perasaan, pesan dalam bentuk puisi rakyat secara lisan dan tulis dengan memperhatikan struktur, rima, dan penggunaan bahasa..

\section{REFERENSI}

Amir, Aminudin. (2013). Sastra lisan Indonesia. Yogyakarta : penerbit Andi.

Andrianingsih. (2015). Analisis fungsi dan makna mantra "Tuturan Sawai" suku Kutai di desa Batu Timbau Kecamatan Batu Ampar. Samarinda : Fakultas Ilmu Budaya.

Anggoro, Hendi. (2011). Struktur Mantra Primbon Ajimantrawara. Semarang: Universitas Negeri Semarang.

Arikunto, Suharsimi. (2010). Prosedur Penelitian Sastra Pendekatan Prektik. Jakarta:PT Rineka Cipta.

Arsyad. (2013). Media Pembelajaran. Jakarta: PT RajaGrafindo Persada.

Chaer, Abdul. (2009). Pengantar Semantik Bahasa Indonesia. Jakarta: Rineka Cipta.

Endraswara. (2013). Metodologi Penelitian sastra Epistemologi, Model, teori, dan Aplikasi.

Jakarta : CAPS (Center For Academic Publishing Service).

Hutomo, Suripan Hadi. (1992). Panduan Penelitian Sastra Daerah. Jakarta : depdikbut.

Keraf, Gorys. (2009). Diksi dan Gaya Bahasa. Jakarta: Gramedia Pustaka Umum.

Moleong, Jexy J. (2014). Metodologi Penelitian Kualitatif Edisi Revisi. Bandung: PT Remaja Rosdakarya.

Nurgiyantoro, (2013). Penilaian Pembelajaran Bahasa. Yogyakarta: BPFE.

Pudentia, MPSS (Ed). (2008). Metodologi Kajian Sastra Lisan. Jakarta : Asosiasi Tradisi Lisan. 
Pradopo, Rahmat Djoko. (2013). “Beberapa Teori Sastra, Metode Kritik, dan Penerapannya”. Yogyakarta: Pustaka Pelajar.

Rafiek. (201)5. Teori Sastra Kajian Teori dan Praktik. Bandung: PT Refika Aditama.

Rokhmansyah, Alfian. (2014). Studi dan Pengkajian Sastra. Yogyakarta: Graha Ilmu.

Sadikin, Mustofa. (2011). Kumpulan Sastra Indonesia. Jakarta: PT Buku Kita.

Sari, Indah Puspita. (2018). Mantra Pengobatan etnis Tionghoa Marga Lay: Kajian Sturkturalisme. Skripsi. Singkawang: Pendidikan Bahasa dan Sastra Indonesia, Program Strata 1, Sekolah Tinggi Keguruan dan Ilmu Pendidikan STKIP Singkawang.

Sarumpaet. (2010). Pedoman Penelitian Sastra. Jakarta: Yayasan Pustaka Obor Indonesia.

Semi, Atar. (2012). Metode Penelitian Sastra. Bandung: CV Angkasa.

Slavin, Robert. (2014). Cooperative Learning. Bandung: Nusa Media

Sugiyono. (2015). Metode Penelitian Pendidikan. Bandung: Alfabeta

Sukatman. (2009). Butir-Butir Tradisi Lisan Indonesia. Yogyakarta: Laksbang Pressindo.

Sulistyorini, Dwi dan Eggy. (2017). Sastra Lisan. Malang: Madani

Siswantoro. (2014). Metode Penelitian sastra Analisis Struktur Puisi. Yogyakarta: Pustaka Pelajar.

Triani, S. N., Yanti, L., \& Kurniawan, K. (2020). Struktur, Fungsi, dan Makna Mantra Dayak Salako di Desa Bagak Sahwa Kecamatan Singkawang Timur. Cakrawala Linguista, 2(2), 89-94. 